\title{
Faciès céramiques en territoire picton
}

Séverine Lemaître et David Guitton

URL : http://journals.openedition.org/adlfi/3334

ISSN : 2114-0502

Éditeur

Ministère de la culture

Référence électronique

Séverine Lemaître et David Guitton, «Faciès céramiques en territoire picton », ADLFI. Archéologie de la France - Informations [En ligne], Poitou-Charentes, mis en ligne le 01 mars 2009, consulté le 03 mai 2019. URL : http://journals.openedition.org/adlfi/3334

Ce document a été généré automatiquement le 3 mai 2019.

(c) Ministère de la Culture et de la Communication, CNRS 


\title{
Faciès céramiques en territoire picton
}

\author{
Séverine Lemaître et David Guitton
}

Identifiant de l'opération archéologique : 204340

Date de l'opération : 2009 (PC)

La troisième année d'existence du PCR a vu la poursuite des travaux entamés les deux années précédentes. Le groupe de travail compte aujourd'hui une vingtaine de membres actifs issus de structures différentes (université : enseignants-chercheurs et étudiants en Master et en Doctorat, INRAP, CNRS, collectivités territoriales, musées). Les objectifs définis ont été maintenus, entre études analytiques d'ensembles de mobiliers et caractérisation des productions des ateliers de potiers pictons.

\section{Ateliers et productions céramiques en territoire picton}

Les travaux liés aux productions céramiques en territoire picton ont continué en 2009 en particulier sur le site de Louin-la-Martinière dans le département des Deux-Sèvres dans le cadre d'un diplôme de Master 2 soutenu par M. Durquéty à l'université de Poitiers. L'étude réalisée montre une "production diversifiée comprenant des formes soignées et standardisées. Le mobilier céramique recueilli sur le site en dehors des productions, n'apporte pas d'éléments de datation fiables. Mais l'analyse du répertoire a montré de nombreuses similitudes avec l'officine de potiers du Pont-du-Jard à Bellefonds dans la Vienne et la boutique du marchand de vases des fouilles des Cordeliers à Poitiers. L'atelier de Louin s'intègre bien dans les faciès régionaux de la seconde moitié du III ${ }^{e} \mathrm{~s}$. et du IV s. apr. J.-C. » (Durquéty, 2009). Comme pour les productions de l'atelier de Gourgé (DeuxSèvres) en 2008, l'année 2009 a vu débuter la caractérisation des céramiques produites à Louin grâce à un programme d'analyses physico-chimiques réalisées en fluorescence $\mathrm{X}$ au laboratoire de Céramologie UMR 5138 « Archéométrie et Archéologie » de Lyon, Maison de l'Orient et de la Méditerranée en collaboration avec A. Schmitt (CNRS). «Soixante 
treize échantillons ont été prélevés et seront traités en deux campagnes d'analyses. Le programme inclut des échantillons provenant de céramiques issues de contextes de consommation, ce qui devrait éclairer la carte de diffusion de cet atelier » (Durquéty, 2009).

La majorité des collections de céramique sigillée conservées au musée Sainte-Croix a fait l'objet d'une publication en 2004 par J.-L. Tilhard. Parmi les pièces prises en compte figurait un des corpus de vaisselles du groupe «Centre-Ouest » les plus importants que l'on connaisse. Il restait à étudier les fragments lisses dépourvus d'estampilles, c'est-àdire ceux appartenant à des vases qui n'en ont jamais comporté ou encore dont la fragmentation fait que la partie estampillée est manquante. Ce travail, mené en juin 2009, par R. Delage, D. Guitton et J.-L. Tilhard a permis de réunir 41 pièces. Elles ont été sélectionnées après un examen critique de leurs caractéristiques techniques (pâtes et vernis), celles-ci devant correspondre en tous points à celles des référents, à savoir pour l'essentiel, les vases moulés. Dans tous les cas, les vaisselles pouvant être confondues avec des vases arvernes ont été écartées.

L'étude de ce lot de vaisselle s'inscrit dans le cadre du projet visant à actualiser et synthétiser l'ensemble des connaissances sur les sigillées du Centre-Ouest. Elle contribue à l'enrichissement des données dans le domaine du répertoire des formes lisses de la période " classique ", apporte une contribution à la question des productions " tardives " et met en évidence l'existence de formes marginales.

En 2009, D.Guitton, en collaboration avec F. Chiron, D. Simon-Hiernard et S. Soulas a poursuivi ses recherches à propos de la production de vases de type « Argonne » au sein des ateliers du groupe des céramiques dites "à l'éponge " du sud du territoire picton (Vienne). Cette étude préliminaire montre que si la région de Civaux doit toujours être considérée comme une zone de production privilégiée, elle ne saurait être exclusive comme semble en témoigner la diversité des pâtes et des aspects de surface observés. L'analyse des répertoires de ces céramiques sans doute d'origine pictonne met en avant des liens forts avec ceux des sigillées d'Argonne. Il est encore difficile de savoir s'il s'agit de simples imitations, ou, de préférence, d'un phénomène plus complexe de transferts de compétences commun aux territoires du nord de la Gaule.

\section{Sites de consommation}

L'acquisition des faciès passant par l'analyse détaillée d'ensembles de mobiliers céramiques mis au jour sur les sites de consommation a continué en 2009. La période de La Tène finale est illustrée dans les travaux du PCR par les études menées respectivement par P. Maguer sur les mobiliers céramiques du site des Natteries (Maine-et-Loire) et par G. Landreau sur la façade littorale atlantique de la cité des Pictons.

À Poitiers, l'étude menée par S. Lemaître, en collaboration avec M.-C. Arqué, J. Bidault et A.-E. Auger du mobilier amphorique livré par les fouilles de la Médiathèque (1992 et 1993), a permis d'élargir le champs géographique des approvisionnements de la capitale pictonne entre les dernières décennies du $\mathrm{I}^{\mathrm{er}} \mathrm{s}$. av. J.-C. et la fin du Haut-Empire. Des amphores africaines précoces à sauce et conserve de poisson ont pu être identifiées, ainsi que les premiers conteneurs à vin originaires de la région d'Ephèse (Ionie). Le faciès général défini pour le site de la rue de la Marne à Poitiers en 2008 reste globalement 
inchangé, les quelques découvertes mentionnées ci-dessus gardant un caractère anecdotique.

Dans les agglomérations secondaires, la connaissance des faciès céramiques s'est approfondie dans la partie orientale du territoire picton grâce aux études réalisées par A.E. Auger sur les mobiliers céramiques mis au jour sur le site de Saint-Pierre-les-Églises, en particulier celui d'une cave incendiée ayant livré des quantités importantes de céramiques de stockage. De même, sur le site du Gué-de-Sciaux à Antigny (Vienne), l'analyse des amphores mises au jour à l'emplacement du sanctuaire, a enrichi le faciès d'approvisionnement du site (étude S. Lemaître).

Enfin signalons la mise en place au laboratoire d'Archéologie de l'UFR Sciences Humaines et Arts de l'université de Poitiers d'une collection de céramiques de référence concernant à la fois les productions des ateliers de potiers pictons et les grandes catégories de céramiques importées en territoire picton : amphores méditerranéennes, sigillées etc.

Un nouveau projet de programme collectif de recherche a été déposé auprès du service régional de l'Archéologie Poitou-Charentes pour les années 2010-2012 afin de mener à terme les recherches amorcées et accueillir le Congrès international de la SFECAG à Poitiers en 2012.

GUITTON David et LEMAIITRE Séverine

INDEX

Index géographique : Poitou-Charentes

operation Projet collectif de recherche (PCR)

Thèmes : amphore, amphore africaine, analyse des matériaux, atelier de potier, céramique à l'éponge, céramique gallo-romaine, céramique romaine, fluorescence $\mathrm{X}$, production, sigillée

d'Argonne, sigillée de Gaule du Centre, vaisselle

\section{AUTEURS}

\section{SÉVERINE LEMAÎTRE}

